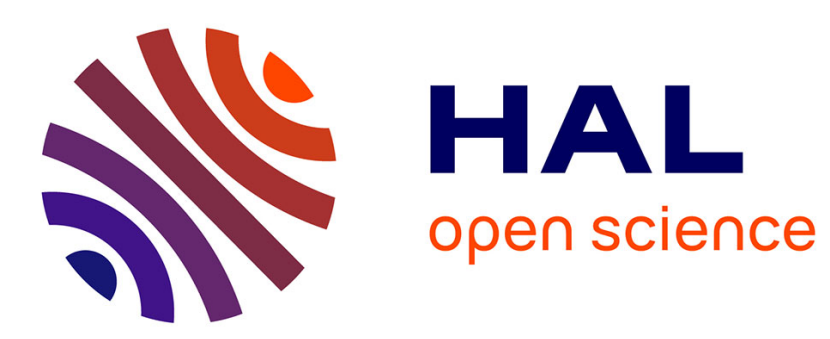

\title{
Some observations on the expression of temporal relations in future time relative clauses
}

Ilse Depraetere

\section{To cite this version:}

Ilse Depraetere. Some observations on the expression of temporal relations in future time relative clauses. Linguistics, 1994, 32 (3), pp.459-473. halshs-00625759

\section{HAL Id: halshs-00625759 \\ https://shs.hal.science/halshs-00625759}

Submitted on 22 Sep 2011

HAL is a multi-disciplinary open access archive for the deposit and dissemination of scientific research documents, whether they are published or not. The documents may come from teaching and research institutions in France or abroad, or from public or private research centers.
L'archive ouverte pluridisciplinaire HAL, est destinée au dépôt et à la diffusion de documents scientifiques de niveau recherche, publiés ou non, émanant des établissements d'enseignement et de recherche français ou étrangers, des laboratoires publics ou privés. 


\section{Some observations on \\ the expression of temporal relations in future-time relative clauses ${ }^{1}$}

ILSE DEPRAETERE

Abstract

This paper deals with the question whether the syntactic difference between restrictive relative clauses $(R R C)$ and nonrestrictive relative clauses $(N R R C)$ results in different tense systems determining the choice of verb forms to indicate future time. It is shown that future-time NRRCs only allow the use of absolute tenses to express temporal relations, whereas in $R R C s$, relative tenses can be used as well. However, there are a number of constraints on the use of relative tenses even in $R R C s$, a phenomenon that has escaped most linguists' attention. In this paper, a survey is made of factors that determine whether or not it is possible to use relative tenses to refer to future-time situations in RRCs.

\section{Introduction}

It is generally known that the use of a future tense in temporal clauses results in ungrammaticality:

(1) a. *I will write to you when I will have time.

Reference to a future-time situation is established by means of a present tense or a present perfect, as in (1b) and (1c):

(1) b. I will write to you when I have time.

c. I will write to you as soon as I have received the news.

The difference in tense choice between time clauses and main clauses, where a future tense can be used, is related to the different syntactic status of the clauses: a temporal clause is syntactically subordinated to the main clause, whereas a main clause is independent. Having said this, one might wonder if the tight syntactic bonds between a restrictive relative 
clause (RRC) and a main clause and the loose syntactic bonds between a nonrestrictive relative clause (NRRC) and a main clause also result in different tense systems being used. This issue will be addressed in some detail in the present paper, with special emphasis on the principles determining the use of tense in RRCs. Our comparison of RRCs and NRRCs will to a great extent be based on an analysis of corpus examples extracted from the Lancaster-Oslo-Bergen corpus (LOB), the Survey of English Usage (SEU), and the Wall Street Journal (WSJ) corpus. For each of the examples, we will examine whether the verb form (e.g. the present tense or the future tense) used to indicate future time is the only available option and will try to explain possible restrictions on the use of particular forms. Most of the observations that will be made are not generalizations in the sense that they are hard and fast rules to which there are no exceptions; they are rather tendencies, which, subtle though they sometimes are, nevertheless influence the use of tense. The views expressed are the result of ample consultation of native speakers of British English. ${ }^{2}$

The fact that there are two possible systems to indicate future time has not gone unnoticed. Wekker (1976), for instance, uses the term future subordination to capture the tense system in conditional and temporal clauses. In this case, "tense-usage can be said to be non-deictic or temporally unmarked" (Wekker 1976: 72), which means that the speaker decides to temporally relate the situation to another future-time situation rather than to the time of speech. Along with Declerck (1991), we might say that in the former case, the situation is temporally subordinated to the main-clause situation (i.e. a "relative" or "anaphoric" verb form is used); in the latter case, the time of speaking functions as time of orientation (TO) ${ }^{3}$ (i.e. an "absolute" or "deictic" verb form is used). Allen (1966) also explicitly makes the generalization that the use of the present tense/present perfect to refer to a situation that is simultaneous with/anterior to a future-time situation is not exceptional or due to "will deletion," as has been claimed by other linguists. Just as the past perfect/past tense is used to express anteriority to/simultaneity with another situation in the past tense, so the present perfect/present tense is used to express anteriority to/simultaneity with a future-tense situation. Declerck (1991) provides a comprehensive framework in which the possibilities generated by the English tense system are described systematically. In what he calls the postpresent sector, ${ }^{4}$ relative tenses can be used to express temporal relations: simultaneity is expressed by means of the present tense (cf. [2a]), anteriority is expressed by means of the present perfect (cf. [2b]) or the past tense (cf. [2c]), and posteriority by means of the future tense (cf. [2d]):
(2) a. She will say she does not recognize him.

b. She will say she has stolen the money.

c. She will say she stole the money the day before.

d. She will say she will never leave him again.

The verb system in the subclauses in (2) constitutes an example of what Declerck calls a shift of temporal perspective (1991: 24); that is, the tense system typical of a particular sector (in this case the present sector) is used to locate situations in another sector (in this case the postpresent sector). The time of the situation to which the subclause situation is temporally subordinated is each time treated as if it were the moment of speech $\left(t_{0}\right)$. This explains why the system of tenses used to express temporal relations in the postpresent sector is the same as the system of absolute tenses, used to locate situations in the four sectors. However, it must be stressed that the tense forms used to express anteriority/simultaneity/posteriority in the postpresent sector in (2a) to (2d) are not used as absolute tense forms. They are relative tense forms, which relate a situation to a future TO. To indicate the set of tenses used to temporally subordinate situations to a future TO, Declerck (191: 50) uses the label present perspective system (PPS), because in this system the future TO is treated as if it were $t_{0}$. The speaker may also choose to relate the newly introduced situations to the "real" $t_{0}$ (rather than to the postpresent "pseudo- $t_{0}$ "). In this case, he uses absolute tenses. Declerck calls this option the future perspective system (FPS):

(3) a. There will be a party next Tuesday. John and Mary will also be there.

b. They will give her a painting. They will have bought it at Sotheby's.

c. She will be rather upset when she hears she will not be allowed to attend the meeting.

The future tense will be in (3a) explicitly indicates that the situation it refers to is located in the postpresent sector. Will have bought is called an absolute-relative tense because apart from locating the situation in the postpresent sector, which accounts for the label absolute, it also expresses anteriority with respect to the postpresent "pseudo- $t_{0}$," which accounts for the label relative. The future perfect is not an absolute tense in the sense that it locates its situation in one of the sectors and in doing so relates it directly to $t_{0}$. Rather, it relates its situation as anterior to a postpresent $\mathrm{TO}$ and in doing so leaves vague the temporal relation between the situation in question and $t_{0}$. For example, the situation referred to in the second sentence of $(3 b)$ could lie before or after or 
could coincide with $t_{0}$. Will be allowed in (3c) is ambiguous between an absolute tense and a relative tense expressing posteriority with respect to the main-clause situation.

\section{The expression of temporal relations in future-time $\mathrm{RCs}$}

\subsection{General principle}

The PPS-FPS distinction enables Declerck to explain why will cannot normally be used in temporal and conditional clauses: it is because these clauses must be temporally subordinated to the main-clause situation that FPS forms cannot be used. The choice between FPS and PPS for RRCs and NRRCs is not a free one either. As Declerck points out, NRRCs appear to exclusively use the FPS, whereas in RRCs, either system can be used, though not without any constraints:

"In subclauses whose situation is not represented as temporally dependent on that of the matrix, the Future Perspective System is used. Nonrestrictive relative clauses are always of that type (...) In some types of subclause (e.g. restrictive relative clauses) the situation may or may not be represented as temporally dependent on the situation of the matrix" (Declerck 1991: 55):

(4) a. I will ask John, who will know the answer tomorrow $\left({ }^{*}\right.$ knows $)$ (Declerck 1991: 55) (NRRC).

b. I will ask John, who will have heard the news by then (*has heard) (Declerck 1991: 55) (NRRC).

(5) When she gets paid next month she will tell us that she will soon buy a new hat with the money she has saved/will have saved from that paycheck (Declerck 1991: 55) (RRC).

The examples given in (6) also show that RRCs and NRRCs differ with respect to the verb forms they allow to indicate future time. The context could be one in which someone is given a description of a person to whom he is supposed to deliver a message:

(6) a. You will meet John, who will be wearing a red cap (NRRC).

b. You will meet John, who is wearing a red cap (NRRC).

c. You will meet a man who will be wearing a red cap (RRC).

d. You will meet a man who is wearing a red cap (RRC).

The present tense in the NRRC in (6b), unlike that in its restrictive counterpart in (6d), is not interpreted as referring to a future time. Sentence (6b) is interpreted as follows: tomorrow you will meet John, who is wearing a red cap now. In other words, the present tense establishes present-time reference; reference to the future requires the use of the FPS in the NRRC. In the RRC in (6d), on the other hand, the tight syntactic bonds between the main clause and the RRC safeguard a correct, that is to say, a future-time interpretation of the present tense. The future tense is a possible, but not the only, option. Example (7) illustrates the same principle:

(7) a. It is not impossible that some time or other a bomb will explode which is hidden (will be hidden) in our building (RRC) (Declerck 1991: 56).

b. It is not impossible that some time or other an atomic bomb will explode, which will be hidden (* ?? is hidden) in our building (NRRC).

The present tense establishes future-time reference in the RRC; the future tense need not be used because the context makes it sufficiently clear that there is reference to a bomb that will be hidden at a future moment in time. This is not the case in the NRRC, in which the use of the present tense results in a clash: the main clause refers to a future time at which the bomb will be hidden, whereas the only temporal interpretation the NRRC allows is one according to which the bomb is already hidden in the building. If the sentence is to make sense, the future tense has to be used in the NRRC. In other words, the examples in (7) illustrate the same tendency as those in (6): NRRCs require the use of the FPS, whereas the PPS can be used in RRCs. In the following example, the RC situation is anterior to the postpresent TO:

(8) a. If the IRS admits its error and the charges have been paid, it will reimburse a taxpayer who hasn't refused to give timely answers to IRS inquiries or hasn't contributed to continuing or compounding the error (WSJ).

b. If the IRS admits its error and the charges have been paid, it will reimburse Mr. Smith, who won't have refused ( $\neq$ hasn't refused $)^{5}$ to give timely answers to IRS inquiries or hasn't contributed to continuing or compounding the error.

The only possible interpretation of the present perfect in $(8 b)$ is one in terms of an absolute tense locating the NRRC situation in the prepresent sector. The present perfect in the RRC allows the same interpretation, but it may also belong to the PPS, in which case it is a relative tense that temporally subordinates its situation to the TO established in the main clause. This example again proves that a NRRC referring to the future has to use an FPS form. 
As I see it, the impossibility of using the PPS in NRRCs is due to (a) the nature of the tenses of the PPS and (b) the function of NRRCs. The nature of the tenses involved is important for the use of tense in the postpresent sector because the temporally subordinated PPS verb forms can also be interpreted as absolute tenses. For instance, the present tense can be used as a PPS form expressing simultaneity with a future-tense situation and as an absolute tense locating a situation in the present sector. Similarly, the present perfect and past tense may function as PPS forms as well as locating a situation in the prepresent sector and past sector respectively. The unmarked interpretation of the present tense is that it refers to present time. This element, together with the fact that NRRCs give additional, relevant information and the fact that "other things being equal, statements about the present moment are more relevant than those about other times" (Comrie 1985: 41-42) (i.e. facts are more important than predictions), explains why present-tense NRRCs are interpreted as having present-time reference. A similar line of reasoning applies to past-tense and present-perfect NRRCs. In this case, it is the preference for a situation with a factual character (because it is anterior to $t_{0}$ ) rather than a prediction (because the situation is anterior to the pseudo- $\mathrm{t}_{0}$ ) that lies at the origin of the past/prepresent-sector interpretation of the verb forms. However, the ultimate question to be answered is whether the principles determining the use of tense in postpresent RRCs and NRRCs are different. My answer is that forms that could be interpreted as PPS forms will be interpreted as having present/ past/prepresent-time reference whenever possible, no matter whether they occur in a RRC or a NRRC. From this point of view, RRCs and NRRCs do not differ. For instance, when we change the NRRCs given in Declerck (1991) into RRCs, it becomes clear that the latter type of clause does not always allow temporal subordination either:

(9) I will ask the man who will know (?? knows) the answer tomorrow (cf. [4a]).

The ungrammaticality of the PPS form is due to a certain degree of incompatibility of two elements: an absolute present tense accompanied by a future-time adverbial can be used to indicate future time provided there is reference to a situation that is predictable (e.g. The train leaves at $5 o^{\prime}$ clock). Know the answer is, on its unmarked interpretation, not predictable. There is therefore a clash between the situation referred to and the type of situation needed to establish future-time reference by means of a present tense. ${ }^{6}$ Moreover, a shift of perspective involves an absolute, not a relative, tense, which means that even if knows were acceptable, it would have to be classified as an absolute tense and not as belonging to the PPS. By tomorrow in (10) requires the use of an absoluterelative tense, that is, the future perfect:

(10) I will ask the man who will have heard (?? has heard) the answer by tomorrow (cf. [4b]).

Knows and has heard are acceptable only in a specific context. If a contest is to take place tomorrow, and it is certain now that there will be one man who will know/will have heard the answer to the question and another man who will not, it is possible to say, $I$ will ask the man who knows/has heard the answer tomorrow. ${ }^{7}$ Even if there are no adverbials present, knows and has heard do not get a postpresent-sector interpretation:

(11) a. I will ask the man who will know ( $\neq$ knows) the answer.

b. I will ask the man who will have heard ( $\neq$ has heard) the answer.

The adapted versions of Declerck's examples given in (4) show that there are also restrictions on the choice of verb forms in RRCs, that is, it is not the case that PPS and FPS forms are always substitutable in RRCs. From that point of view, there is a certain degree of similarity between the two types of RC. However, RRCs and NRRCs differ in the sense that the likelihood of verbs belonging to the PPS being "misinterpreted" (i.e. as locating the situation in one of the other sectors) is far greater in NRRCs than in RRCs: "misinterpretation" is the rule in NRRCs, whereas it is merely possible in RRCs. This has to do with the independent syntactic status of NRRCs. The importance of the tight syntactic links between the main clause and the RRC can indeed not be denied; it is basically because the syntactic ties between RRCs and their (future-tense) main clause are close that present-tense forms, for example, can be interpreted as having future reference.

The above observations justify the conclusion that the tense system in postpresent RCs is determined by the different syntactic status of RRCs and NRRCs: in NRRCs, unlike RRCs, the FPS is the only option that can be used. It has also become clear that there are constraints on the use of PPS forms in RRCs. The next section is therefore aimed at listing some of the factors that influence the interpretation of verb forms in RRCs.

\subsection{Factors determining (mis)interpretation of verb forms in $R R C s$}

Pragmatic, especially situational, knowledge determines whether it is possible to use PPS forms in RRCs. That is, if the hearer knows that the 
RRC situation is located in the future, the PPS forms will be understood "correctly," that is, as having future-time reference. This implies that it is impossible to determine in advance when the PPS forms will be misinterpreted as not referring to the postpresent sector: what is mutually manifest (Sperber and Wilson 1986: 42) in one context (i.e. postpresentsector reference) is not necessarily so in another. ${ }^{8}$ As the context changes with every utterance, it cannot be predicted how PPS forms will be understood. However, the following are some elements that influence the interpretation of PPS forms in RRCs:

2.2.1. Linear order of the main clause and the $R C$. The order in which the clauses are reported influences the interpretation of the verb forms. It seems reasonable to expect that whenever a RC precedes the main clause, the present tense will automatically be interpreted as an absolute tense referring to a present-sector situation. If we want to locate the RC situation in the postpresent sector, the future tense has to be used:

(12) a. This executive says that business should hold up even during a recession. And with fewer airlines remaining, he concludes, "those of us who are left will make a lot of money" (WSJ).

b. This executive says that business should hold up even during a recession. And with fewer airlines remaining, he concludes, "those of us who will be left will make a lot of money."

If the executive wants to refer to the airlines who will be making a lot of money because competitors will go into failure due to the impending recession, he will have to use a future tense, as the only interpretation the present tense allows is one in terms of present-time reference. However, the sequential order RRC-main clause does not always require the use of the FPS in the RC. In the following cases, PPS forms can be used:

a. When the main clause future tense immediately follows the RC present tense, a present tense is more readily interpreted as a PPS form:

(13) The way in which she behaves will reveal that she does not feel at ease.

As behaves is closely followed by will reveal, the possible present-sector interpretation of the RC situation will quickly be abandoned in favor of a postpresent-sector interpretation.

b. When the RC preceding the main clause is couched in a future-time context, the use of FPS forms in the RC may not be necessary:
(14) a. In addition to the valuable life assurance that this plan provides, once you reach age 60 you will receive a considerable cash sum, amounting on current bonus rates to at least all the premiums you have paid - and maybe much more. The cheque you receive will be entirely taxfree, under current legislation (SEU).

It is not merely because will be immediately follows receive that the PPS can be used in the RC. The context preceding receive clearly indicates that there is reference to a check that will be received in the future. The following example is similar:

(14) b. Richard Dimbleby will interview people in each island from a point in Guernsey, and the musical records they ask for will be played from a London studio (Buyssens 1968: 50).

c. When the RC has conditional connotations, PPS forms are interpreted correctly:

(15) a. But once the deductible goes below $\$ 1,000$ the price of additional coverage begins to soar. Policyholders who choose a $\$ 100$ rather than a $\$ 250$ deductible will pay $\$ 2$ (WSJ).

b. The widow of a man who has paid graduated contributions will get a graduated addition to her flat-rate retirement pension equal to one-half the graduated part of the pension her husband had earned or was earning when he died (LOB).

2.2.2. Influence of lexical material. The presence of certain words referring to entities that already exist at the moment of speech may influence the interpretation of the verb form:

(16) a. She will retain in the vitality of her spirit, in the vigour of her language, in the occasional peasant quality of humour, a strength which her children have not and towards which they have at times something of a sophisticated and urbanized "neshness" (adapted from SEU). 9

b. She will retain in the vitality of her spirit, in the vigour of her language, in the occasional peasant quality of humour, a strength which her children will not have and towards which they will at times have something of a sophisticated and urbanized "neshness."

There are many constituents between the main-clause future tense and the RC present tense, which may contribute to establishing a presenttime interpretation of have. However, other factors play a more important 
role in this respect: (a) there is reference to children, who already exist at the time of speaking, and who therefore already possess strength; (b) one can only retain something if one possesses it already. In other words, retain suggests the idea of an existing (present-time) characteristic. When we replace children by future children, the present tense cannot establish a future-time interpretation even if the intervening constituents are left out:

(17) a. She will retain in the vitality of her spirit, in the vigour of her language, in the occasional peasant quality of humour, a strength which her future children ?? have not and towards which they have at times something of a sophisticated and urbanized "neshness" (adapted from SEU).

b. She will retain in the vitality of her spirit, in the vigour of her language, in the occasional peasant quality of humour, a strength which her future children will not have and towards which they will have at times something of a sophisticated and urbanized "neshness."

The use of the future tense in both the RC and the main clause may be required because the element of prediction is strongly present: (a) she will have children, (b) her future children will behave in a particular way. The point is corroborated by Lakoff (1971), who claims that (18) is odd because the relative pronoun who requires "that the person referred to either be presupposed to be alive at the time referred to in the relative clause, or thought of as a human being" (1971: 331):

(18) a. *We have just found a good name for our child, who we hope will be conceived tonight (1971: 331).

b. We have just found a good name for our child, who we hope will grow up to be a good citizen after he is born (1971: 331).

2.2.3. Definite vs. indefinite antecedent. The (in)definiteness of the antecedent also plays a role in the temporal location of a present-tense RC:

(19) a. A left-wing student will seize the microphone, but will be quickly cut off by the official who cuts the cord (definite antecedent).

b. A left-wing student will seize the microphone, but will be quickly cut off by an official who cuts the cord (indefinite antecedent).

Out of context, one is much more inclined to interpret the present tense as indicating present time in (19a) than in (19b). This preference can

only be ascribed to the difference in definiteness of the antecedent. When the definite article is used, one gets the impression that there is reference to a person whose task it is to cut the cord whenever something irregular happens; the NP refers to a habitual situation. When the indefinite article is used, this interpretation is less likely, the unmarked interpretation being that there is reference to a future-time official, who, forced by the particular situation, happens to cut the cord. The reason why a presenttense RRC embedded in a definite NP is more likely to be interpreted as having present-time reference may be related to the following: a definite NP indicates that the speaker believes that the hearer is in a position to identify the referent. The speaker may choose to add a modifier, in this case, a RRC, to help the hearer find out who the speaker is talking about. Accordingly, the speaker will use all the information given to him to establish reference. As the unmarked interpretation of the present tense is present time, a present-tense RC with a definite antecedent will more readily be interpreted as referring to the present time. Eager to assign reference, the hearer will carry out this task with as little effort as possible. This explains why it is rather likely that the present tense will be interpreted as indicating present time if the noun has not been mentioned before in a future-time context: a present-time interpretation is the most easily accessible interpretation. The corresponding $\mathrm{RC}$ with an indefinite antecedent does not indicate that the speaker assumes that the hearer can identify the referent. Accordingly, there will be no similar readiness to interpret a present tense in an indefinite NP as referring to the present sector.

Example (20) also shows that the definite article favors a presentsector interpretation of a present-tense RC:

(20) a. Lady Foxglove will look up with a busy smile at the enormous figure who is clearing (will be clearing) his throat importantly (adapted from SEU). ${ }^{10}$

b. Lady Foxglove will look up with a busy smile at an enormous figure who is clearing (will be clearing) his throat importantly.

Out of context, the present tense in (20a) is more likely to have presentsector reference than that in $(20 \mathrm{~b})$.

The conclusion from this section is that the definiteness of the NP is an important factor that may hamper a future-time interpretation of PPS forms.

2.2.4. Aspect and Aktionsart. A state (cf. [21]) in the present tense is more likely to be interpreted as an absolute tense than an activity (cf. [22]) or accomplishment (cf. [23]) referred to by a present tense: 
(21) a. I will be Head of the Department in which she is $\left({ }^{*}\right.$ is being) research assistant, so I will know her quite well.

b. I will be Head of the Department in which she will be research assistant, so I will know her quite well.

(22) a. He will be judged on the way in which he behaves (is behaving).

b. He will be judged on the way in which he will behave.

(23) a. He will throw the corkscrew at the person who opens (is opening) the bottle.

b. He will throw the corkscrew at the person who will be opening the bottle.

As present-time reference is likely to result in a progressive form being used (cf. [22a], [23a]), the nonprogressive forms in the (a) examples are more likely to be understood as PPS forms in (22) and (23) than the present tense in (21a), which cannot be used in the progressive.

2.2.5. Interaction of different factors. It follows from the above discussion that principles may cooperate to establish a particular interpretation. In other cases, one principle may be overruled by another. In this section, some more examples will be given to illustrate how the different principles may interact:

(24) The man she marries will have to be rich (Leech 1971: 65).

The $\mathrm{RC}$ precedes the main clause and is embedded in a definite NP. The NP will first be interpreted as referring to a well-identified man who exists at the time of speaking. However, as we read on, this option has to be abandoned; it becomes clear that the speaker is defining a particular kind of man, that is, one she will want to marry: a specific but not yet found exemplar. The present tense can be used because the main-clause future tense immediately follows the RC present tense. Moreover, the $\mathrm{RC}$ also has a conditional connotation: if he is to marry her, he will have to be rich. The interaction between the different tendencies is also particularly clear in the following example:

(25) Some thought that the result would be all sorts of horrible illnesses brought on by the confined atmosphere. "The shareholders who travel by it will be so heartily sick, what with foul air, smoke and sulphur, that the mention of a railway will be worse than Ipecacuanha," wrote an anti-railway industrialist when it was proposed to build the Box Tunnel (LOB).

As in the case of (24), several factors contribute to establishing a postpresent-sector interpretation of the $\mathrm{RC}$ in spite of the fact that the SC precedes the main clause: (a) the context makes it clear that the Box
Tunnel has not yet been built and that accordingly there is reference to prospective travellers, (b) the main-clause verb follows the SC verb closely, (c) if the speaker wanted to establish present-time reference, he would be more inclined to use a progressive form.

\section{Conclusion}

The above discussion has revealed that the exclusive use of the FPS in NRRCs should be ascribed to (a) the function and syntactic status of NRRCs (i.e. a NRRC is syntactically relatively independent of the main clause), and (b) the intrinsic nature of PPS forms (i.e. PPS forms may be mistaken for absolute tenses). Accordingly, in NRRCs, forms that could be understood as belonging to the PPS are always interpreted as referring to sectors other than the postpresent. In RRCs, on the contrary, they are likely to establish postpresent-time reference. It follows from the observations made that the question I set out to answer, do RRCs and NRRCs differ in the ways they express temporal relations in the postpresent sector, cannot be answered with a straightforward yes or no. The linguists who have touched upon this issue (Allen 1966, Declerck 1991) have basically concentrated on the differences, but I hope to have shown that this is only a partial truth. There is similarity in the sense that forms that could be interpreted as PPS forms may be "misunderstood" in RRCs as well as in NRRCs. However, the syntactic difference between RRCs and NRRCs results in the use of PPS forms in NRRCs being altogether ruled out, whereas PPS forms may be "misinterpreted" in RRCs but are not necessarily so. The examples given in section 2.2 illustrate some of the factors that influence the interpretation of the present tense in RRCs, that is, the order in which the clauses are given (section 2.2.1), the lexical material used (section 2.2.2), the (in)definiteness of the antecedent (section 2.2.3), and the Aktionsart and aspect of the clause (section 2.2.4). It has also become clear that it is rather difficult to make generalizations; a number of tendencies can be observed, but pragmatic, especially contextual, knowledge is probably the most important factor in this respect.

Received 3 January 1994

Revised version received

Catholic University of Leuven 
1. I wish to thank Prof. J. Buysschaert, Prof. R. Declerck, and the two anonymous referees for their comments on an earlier version of this paper. Correspondence address: Departement Linguistiek, Katholieke Universiteit Leuven, Campus Kortrijk, B-8500 Kortrijk, Belgium.

2. I wish to thank T. Caldicott, J. McMahon, and C. McMahon for their comments on the examples.

3. Declerck defines a time of orientation as "any time that functions as the origin of a temporal relation" (1991: 18).

4. Declerck points out that the tense system of a language makes a.binary distinction (past vs. nonpast) when locating situations in time. The temporal zero point $\left(t_{0}\right)$ divides the nonpast time sphere into three sectors: the prepresent sector, the present sector, and the postpresent sector. The past time sphere does not have an inherent dividing point similar to $t_{0}$ : the past time sphere constitutes one single sector, the past sector. In order to locate a situation in the past, prepresent, present, or postpresent sector, English uses the past tense, the present perfect, the present tense, and the future tense respectively.

5. If a particular verb form is preceded by " $\neq$," this means that it is a grammatical form but it results in a different temporal interpretation.

6. Wekker (1976) also points out that one should be careful not to confuse an absolute present tense with future-time reference and a temporally subordinated present tense with future-time reference: "It should be noted that in dependent clauses, where future subordination occurs, the effect of the resultant use of the simple future present will be the representation of a future event or action as a given fact, but not in the sense that something has been planned or pre-arranged" (Wekker 1976: 89-90). See also Kruisinga (1931: II-1, 132, 134).

7. Notice also that if the RC has conditional connotations, knows/has heard the answer tomorrow becomes acceptable:

(i) I will ask anyone who knows/has heard the answer tomorrow.

8. If the temporal location is mutually manifest to the speaker and hearer, it means that they both know in which absolute sector the relevant situation is located.

9. The example is based on the following sentence: "She retained in the vitality of her spirit, in the vigour of their language, in the occasional peasant quality of her humour, a strength which her children had not and towards which they had at times something of a sophisticated and ubanized "neshness' [soft squeamishness]." As there were insufficient postpresent-sector corpus examples at my disposal, I have chosen to transpose corpus examples to other sectors. The adapted examples have been attested by several native speakers. The possible drawback of using adapted corpus examples is compensated by the fact that such examples are rich in contents. Like the "real" corpus examples, they offer a wealth of data that the non-native mind could not possibly devise itself.

10. The example is based on the following senence: "Lady Foxglove crossed out 'Lilli Marlene' and substituted in her characteristic sloping hand, 'Bless this House, but not too loud or there might be complaints', and looked up with a busy smile at the enormous figure who was clearing his throat importantly: 'Urs summum ze door,' he explained and beamed when Lady Foxglove said: 'You mean there's someone at the door?" " (SEU)
Allen, Robert L. (1966). The Verb System of Present-Day American English. The Hague: Mouton.

Buyssens, Eric (1968). Les deux aspectifs de la conjugaison anglaise au XXe siècle. Brussels: Presses Universitaires de Bruxelles.

Comrie, Bernard (1985). Tense. Cambridge: Cambridge University Press.

Declerck, Renaat (1991). Tense in English: Its Structure and Use in Discourse. London: Routledge.

Kruisinga, E. (1931). A Handbook of Present-Day English, vol. 2, English Accidence and Syntax 1. Groningen: Noordhoff.

Lakoff, George (1971). Presupposition and relative well-formedness. In Semantics: An Interdisciplinary Reader, Danny D. Steinberg and Leon Jacobovits (eds.), 329-340. Cambridge: Cambridge University Press.

Leech, Geoffrey (1971). Meaning and the English Verb. London: Longman.

LOB (1991). Lancaster-Oslo/Bergen corpus of British English. In The ICAME Collection of English Language Corpora. Bergen: Norwegian Computing Center for the Humanities.

Prince, Elien F. (1982). The simple futurate: not simply progressive futurate minus progressive. In Papers from the 18th Regional Meeting of the Chicago Linguistic Society, Kevin Tuite, Robinson Schneider, and Robert Chametzky (eds.), 453-465. Chicago: Chicago Linguistic Society.

SEU (1980). Survey of English usage. A Corpus of English Conversation, Jan Svartvik and Randolph Quirk (eds.). Lund: Gleerup.

Sperber, Dan; and Wilson, Deirdre (1986). Relevance. London: Blackwell.

Wekker, Herman (1976). The Expression of Future Time in Contemporary British English. Amsterdam: North-Holland. 